trường hợp bệnh nhân nào tái phát huyết khối tĩnh mạch não, huyết khối tĩnh mạch tạng và tắc mạch phổi. Trong số 38 bệnh nhân cũng chưa quan sát được biến cố chảy máu lớn nào sau 12 tuần sử dung Rivaroxaban. Tác giả Ferro JM và cộng sự cũng quan sát được trong nghiên cứu của mình trên bệnh nhân huyết khối tĩnh mạch não, tỉ lệ hồi phục tốt mRS lí tưởng từ 0-1 điểm trong nhóm dùng thuốc chống đông thế hê mới sau 24 tuần là $91,5 \%$ và tỷ lệ chảy máu lớn thấp $1,7 \%[6]$.

\section{KẾT LUÂNN VÀ KHUYẾN NGH!}

Nghiên cứu trên 38 bệnh nhân huyết khối tĩnh mạch não điều trị giai đoạn cấp với Heparin trọng lượng phân tử thấp sau đó duy trì Rivaroxaban $20 \mathrm{mg} / \mathrm{ngày}$ trong 12 tuần, chúng tôi nhận thấy: Tuổi trung bình của nhóm nghiên cứu là 42,4 $\pm 14,8$ tuổi, nữ có độ tuổi mắc trẻ hơn nam và tỉ lệ nam/ nữ là 1,2 . Khởi phát bệnh có thể cấp tính, bán cấp hoặc mạn tính trong đó khởi phát bán cấp thường gặp nhất chiếm $79,1 \%$. Triệu chứng lâm sàng của bệnh rất đa dạng và không đặc hiệu, nhiều nhất là đau đâuu chiếm 94,7\%. Tổn thương nhồi máu não chiếm $31,6 \%$, chảy máu não $21,1 \%$ và nhồi máu não chuyển dạng chảy máu $18,4 \%$. Vị trí huyết khối thường gặp ở những xoang lớn, trong đó hay gặp nhất là xoang dọc trên $73,7 \%$, xoang ngang $63,2 \%$ và xoang sigma $47,4 \%$. Đa số huyết khối ở nhiều xoang đồng thời chiếm tới $71,1 \%$, ít khi gặp đơn độc 1 xoang.

Bước đầu đánh giá hiệu quả của Rivaroxaban trong điều trị huyết khối tĩnh mạch não sau 12 tuần theo dõi điều trị khá khả quan. Tỷ lê bênh nhân hồi phuc tốt có điểm mRS từ 0-1 điểm sau 12 tuần chiếm 94,7\%. Tỷ lệ tái phát các sự kiện huyết khối tĩnh mạch thấp 2,6\%.

\section{TÀI LIÊU THAM KHẢO}

1. Gustavo Saposnik, Fernando Barinagarrementeria, Robert D Brown Jr, et al. (2011). Diagnosis and management of cerebral venous thrombosis: a statement for healthcare professionals from the American Heart Association/American Stroke Association. Stroke, 42 (4), 1158-1192.

2. Jonathan $M$ Coutinho, José M Ferro, Patrícia Canhao, et al. (2009). Cerebral venous and sinus thrombosis in women. Stroke, 40 (7), 2356-2361.

3. Lê Văn Thính, Trịnh Tiến Lực (2010). Nhân xét một số đặc điểm lâm sàng, cận lâm sàng và điêu trị huyết khối tĩnh mạch não. Tập san Hội Thần kinh hoc Viêt Nam, 2, 10.

4. Trịnh Tiến Lực (2020). Nghiên cứu đặc điểm lâm sàng và hình ảnh học của bệnh nhân huyết khối tĩnh mach não Luân án Tiến sỹ y hoc, Đai hoc Y Hà Nội.

5. Lê Văn Minh. (2014), Nghiên cứu đặc điểm lâm sàng, hình ảnh não, một số yếu tố ngưy cơ và giá trị cúa D-Dimer trong chẩn đoán huyết khối tính mach não, Luân án Tiển sỹ Y hoc, Học viện Quân Y.

6. José M Ferro, Jonathan $M$ Coutinho, Francesco Dentali, et al. (2019). Safety and efficacy of dabigatran etexilate vs dose-adjusted warfarin in patients with cerebral venous thrombosis: a randomized clinical trial. JAMA neurology, 76 (12), 1457-1465.

\title{
NGHIÊN CỨU VAI TRÒ TIÊN LƯỢNG CỦA GIÁ TRI HẤP THU CHUẨN 18F-FDG PET/CT Ở BÊNNH NHÂN UNG THƯ BIỂU MÔ VẢY THỰC QUẢN ĐIỀU TRI HOÁ - XẠ TRIỆT CĂN
}

\section{TÓM TẮT}

Mục tiêu: Xác định vai trò các giá trị hấp thu chuẩn của ${ }^{18} \mathrm{~F}-\mathrm{FDG}$ PET/CT trước điều trị trong tiên lượng kết quả hóa - xạ triệt căn ở bệnh nhân ung thư biểu mô vảy thực quản. Đối tượng và phương pháp: Nghiên cứu can thiệp, tiến cứu trên 60 bệnh nhân ung thư biểu mô vảy thực quản $1 / 3$ trên được chụp ${ }^{18}$ F-FDG PET/CT đánh giá giai đoạn trước điêuu trị và chỉ định hoá xạ trị triệt căn. Các giá trị hấp thu

*Bênh viên Trung ương Quân đọi 108

Chịu trách nhiệm chính: Nguyễn Đình Châu

Email: chaunm108@gmail.com

Ngày nhận bài: 18.6.2021

Ngày phản biên khoa hoc: 13.8.2021

Ngày duyệt bài: 20.8.2021

\section{Nguyễn Đình Châu*, Lê Ngọc Hà ${ }^{2}$}

chuẩn ${ }^{18}$ F-FDG của khối $u$ bao gồm SUVmax, SUVmean, SUVpeak. Sử dụng đường cong ROC đế đánh giá ngưỡng SUV tối ưu liên quan tới đáp ứng và sống thêm. Phân tích đường cong Kaplan-Meier để ước tính sống thêm toàn bộ và sống thêm bệnh không tiến triển. Phân tích hồi quy Cox để tìm biến tiên lượng độc lâp với sống thêm. Kết quả: BN có đáp ứng hoàn toàn chiếm $38,3 \%$. Tỷ lệ sống thêm toàn bộ và sống thêm bênh không tiến triển 4 năm lần lượt là $48,6 \%$ và $44,4 \%$. SUVmean u tại ngưỡng 6,1 có giá trị dự báo đáp ứng hoàn toàn với đô nhay $69,6 \%$, độ đăc hiệu 78,4\%, độ chính xác 75\%. SUVmean u > 6,1 là yếu tố tiên lượng độc lập không thuận lợi cho sống thêm toàn bộ ( $H R=6,74, p=0,02)$ và sống thêm bệnh không tiến triển $(H R=6,53, p=0,00)$. Kết luận: Thông số SUVmean của u nguyên phát trên ${ }^{18} \mathrm{~F}-$ FDG PET/CT trước điều trị có thể sử dụng để tiên 
lượng kết quả điều trị ở bệnh nhân ung thư biểu mô vảy thực quản sau hoá - xạ trị triệt căn.

Tư khoá: ${ }^{18} \mathrm{~F}-\mathrm{FDG} \mathrm{PET} / \mathrm{CT}$, giá trị hấp thu chuẩn, ung thư biểu mô vảy thực quản

\section{SUMMARY \\ PROGNOSTIC ROLE OF ${ }^{18}$ F-FDG PET/CT STANDARD UPTAKE VALUES IN ESOPHAGEAL SQUAMOUS CELL CARCINOMA PATIENTS TREATED WITH DEFINITIVE CHEMORADIOTHERAPY}

Objectives: The aim of this study was to investigate whether standard uptake values (SUV) of pre-treatment ${ }^{18} \mathrm{~F}-\mathrm{FDG}$ PET/CT were helpful for predicting the outcomes in esophageal squamous cell carcinoma patients treated with definitive chemoradiotherapy. Materials and methods: Sixty patients with esophageal squamous cell carcinoma who underwent ${ }^{18} \mathrm{~F}-\mathrm{FDG}$ PET/CT and received definitive chemoradiotherapy. ${ }^{18} \mathrm{~F}-\mathrm{FDG}$ SUVs of tumor including SUVmax, SUVmean, SUVpeak were calculated. The receiver operating characteristic curve (ROC) was used to determine the optimal SUVs cut-off value that associated with response and survival. Using Kaplan-Meier for overall survival (OS) and progression-free survival (PFS) analysis. Multivariate analysis of survival was performed using Cox regression. Results: Complete response was achieved in $38,3 \%$. The 4-year overall survival (OS) and progression-free survival (PFS) rates were $48.6 \%$ and $44.4 \%$, respectively. SUVmean with a cut-off value of 6.1 could predict complete response with sensitivity of $69.6 \%$, specificity of $78.4 \%$, and accuracy of $75 \%$. SUVmean $>6.1$ was a unfavorable prognostic factor for OS (HR $=6,74, \mathrm{p}=0.02$ ) and PFS $(H R=6.53, p=0.00)$. Conclusions: Our study suggests that SUVmean of the primary tumor in pretreatment ${ }^{18} \mathrm{~F}-\mathrm{FDG} \mathrm{PET} / \mathrm{CT}$ may be used in predicting the outcomes for esophageal squamous cell carcinoma patients treated with definitive chemoradiotherapy.

Keywords: ${ }^{18}$ F-FDG PET/CT, standard uptake values (SUVs), esophageal squamous cell carcinoma

\section{I. ĐẶT VẤN ĐỀ}

Ung thư thực quản (UTTQ) là bệnh lý ác tính có tiên lượng xấu. Hiện nay, điều trị UTTQ vẫn còn là thách thức lớn, đặc biệt đối với UTTQ $1 / 3$ trên. Theo các nghiên cứu, UTTQ $1 / 3$ trên chiếm tỷ lệ khoảng $10 \%$ với thể mô bệnh học chủ yếu là ung thư biểu mô vảy (90-100\%) [1]. Do ung thư tế bào vảy khá nhạy cảm với tia xa và việc can thiệp ngoại khoa hết sức hạn chế ở thực quản $1 / 3$ trên nên hóa - xạ trị triệt căn là chỉ định hàng đầu cho nhóm bệnh nhân $(\mathrm{BN})$ này.

Để có chỉ định điều trị và theo dõi phù hợp trên từng $\mathrm{BN}$, việc đánh giá giai đoạn và tiển lượng bệnh là yếu tố tiên quyết. ${ }^{18} \mathrm{~F}-\mathrm{FDG}$ PET/CT là phương pháp ghi hình toàn thân được chỉ định trong chẩn đoán giai đoạn ban đầu, lập kế hoạch xạ trị và phát hiện tái phát, di căn. Bên cạnh đó, PET/CT cho phép định lượng hoạt tính chuyển hóa của khối u và các tổn thương di căn nên có thể lượng hóa mức độ đáp ứng điều trị. Một số nghiên cứu gần đây cho thấy các thông số định lượng chuyển hoá ${ }^{18}$ F-FDG như giá trị hấp thu chuẩn (Standard Uptake Values) có vai trò tiên lượng đáp ứng và sống thêm sau điều trị ở bệnh nhân UTTQ [2], [3], [4], [5], [6], [7], [8].

Ở Việt Nam hiện nay, ${ }^{18}$ F-FDG PET/CT đã được ứng dụng trong chẩn đoán và điều trị UTTQ tại nhiều bệnh viện. Tuy nhiên, chưa có công trình khoa học đề cập đến vai trò của ${ }^{18} \mathrm{~F}-$ FDG PET/CT trong tiên lượng sống thêm sau điều trị ở $\mathrm{BN}$ ung thư thực quản. Chính vì vậy, chúng tôi tiến hành nghiên cứu này với mục tiêu xác định vai trò của các giá trị hấp thu chuẩn ${ }^{18} \mathrm{~F}-\mathrm{FDG}$ PET/CT trước điều trị trong tiên lượng kết quả hoá - xạ triệt căn ở bệnh nhân ung thư biểu mô vảy thực quản.

\section{II. Đốl TƯỢNG VÀ PHƯƠNG PHÁP NGHIÊN CỨU}

2.1. Đối tượng nghiên cứu: $60 \mathrm{BN}$ UTTQ biểu mô vảy thực quản $1 / 3$ trên được chẩn đoán xác định bằng mô bệnh học. Các bệnh nhân được chỉ định chụp ${ }^{18} \mathrm{~F}-\mathrm{FDG}$ PET/CT đánh giá giai đoạn trước điều trị và được hóa - xạ triệt căn, theo dõi tại Viện Ung thư - Bệnh viện TƯQĐ 108 từ tháng 5/2017 đên tháng 7/2021.

- Tiêu chuẩn lứa chọn: tuổi từ 18-75, điểm toàn trạng ECOG 0-2, giai đoạn bệnh II-III theo AJCC 7

- Tiêu chuẩn loại trừ: BN có di căn xa, có ung thư kết hợp, đã điều trị xạ trị hoặc hóa chất

\subsection{Phương pháp nghiên cứu:} tiên cứu

- Thiết kế nghiên cứu: nghiên cứu can thiệp,

- Chụp ${ }^{18} \mathrm{~F}$-FDG PET/CT thực hiện trên máy PET/CT Discovery LightSpeed, GE tại khoa Y học hạt nhân, Bệnh viện TƯQĐ 108. Quy trình chụp ${ }^{18} \mathrm{~F}-\mathrm{FDG}$ PET/CT theo hướng dẫn của Cơ quan năng lượng nguyên tử quốc tế năm 2008 [9]. Xử lý hình ảnh ${ }^{18} \mathrm{~F}-\mathrm{FDG} \mathrm{PET} / \mathrm{CT}$ bằng phần mềm $\mathrm{PET}$ VCAR (Pet volume computer assisted reading) trên trạm xử lý Advantage Workstation 4.7 (GE Healthcare). Ghi nhận các thông số chuyển hoá FDG của tổn thương $u$ nguyên phát gồm SUVmax, SUVmean, SUVpeak theo chỉ số khối cơ thể (lean body mass).

- Điều trị hoá xạ trị triệt căn: Các BN được hội chẩn tiểu ban ung thư tiểu hóa thống nhất phác đồ hóa - xạ trị triệt căn. XTĐBL bằng hệ thống máy xa trị gia tốc Varian $C X$, tại khoa Xa trị, Bệnh viện Trung ương quân đội 108. Phác đồ xạ 
trị: tổng liêu $60 \mathrm{~Gy}$ tại u và hạch đại thể, 50,4Gy dự phòng hạch vùng; thời gian điều trị 28 buổi. Phác đồ hóa chất kết hợp: $5 F U$ + Cisplatin x 4 chu kỳ (mối 4 tuânn) hoặc Paclitaxel + Carboplatin AUC2 x 5 tuần

- Đánh giá đáp ứng điều trị sau xa 3 tháng dựa trên nội soi và CT (theo tiêuu chuẩn RECIST 1.1). BN có đáp ứng hoàn toàn khi không còn tổn thương trên nội soi và $C T$.

- Theo dõi sau điều trị: BN được tái khám định kỳ mỗi 3 tháng trong 2 năm đầu và mối 6 tháng trong các năm tiếp theo để đánh giá tiến triển, tái phát, di căn. Các chỉ tiêu theo dõi bao gồm: khám lâm sàng, nội soi thực quản, CT ngực - bung.

- Thời gian theo dõi tính từ thời điểm bắt đầu xa trị. Bệnh tiến triển tính từ khi bắt đầu điều trị tới khi tiến triển tai chỗ - tai vùng hoă̆c di căn. Sống thêm toàn bộ từ khi bắt đâu điều trị tới khi $\mathrm{BN}$ tử vong.

2.3. Xử lý số liệu: các số liệu được xử lý bằng phần mềm SPSS 20.0. Phẩn tích đường cong ROC tìm biến có giá trị dự báo đáp ứng, sống thêm và tính độ nhạy, độ đặc hiệu, độ chính xác. Phân tích đường cong Kaplan-Meier để ước lượng sống thêm toàn bộ và sống thêm bệnh không tiến triển. Phân tích hồi quy Cox đơn biến và đa biến để tìm các biến có ý nghĩa tiên lượng kết quả điều trị. Các biến có $p<0,1$ trong phân tích đơn biến được cho vào phân tích đa biến. Sự khác biệt có ý nghĩa thống kê giữa các biến khi $p<0,05$.

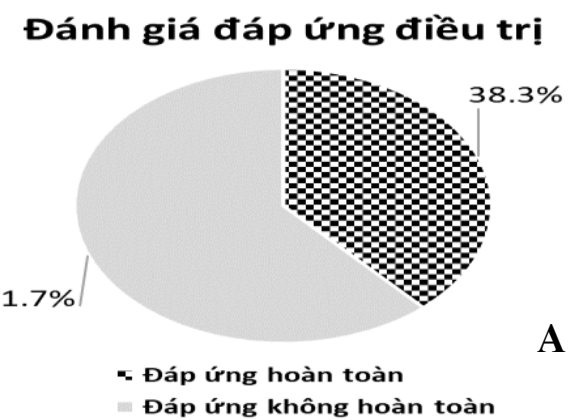

A

Đáp ứng không hoàn toàn
III. KẾT QUẢ NGHIÊN CỨU

Bảng 1. Đặc điểm chung các bệnh nhân

\begin{tabular}{|c|c|c|c|}
\hline \multicolumn{2}{|c|}{ Đặc điểm } & $\begin{array}{c}\text { Số BN (n } \\
=60)\end{array}$ & $\begin{array}{l}\text { Tỷ lệ̂ } \\
(\%)\end{array}$ \\
\hline \multicolumn{2}{|c|}{ Tuối trung bình } & \multicolumn{2}{|c|}{$57,9 \pm 6,9$} \\
\hline \multirow[b]{2}{*}{ Giới } & Nam & 60 & 100 \\
\hline & Nữ & 0 & 0 \\
\hline \multirow{2}{*}{ ECOG } & 0 & 26 & 43,3 \\
\hline & $1-2$ & 34 & 56,7 \\
\hline \multirow{3}{*}{$\begin{array}{l}\text { Mô bệnh học } \\
\text { (Ung thư tế } \\
\text { bào vảy) }\end{array}$} & Độ 1 - 2 & 35 & 58,3 \\
\hline & Độ 3 & 23 & 38,3 \\
\hline & Không phân độ & 2 & 3,4 \\
\hline \multirow{2}{*}{$\begin{array}{l}\text { Giai đoạn } \\
\text { bệnh }\end{array}$} & II - IIIA & 32 & 53,3 \\
\hline & IIIB - IIIC & 28 & 46,7 \\
\hline \multirow{2}{*}{$\begin{array}{l}\text { Phác đồ hóa } \\
\text { trị }\end{array}$} & 5FU/Cisplatin & 12 & 20,0 \\
\hline & $\begin{array}{l}\text { Paclitaxel/ } \\
\text { Carboplatin }\end{array}$ & 48 & 80,0 \\
\hline \multicolumn{2}{|c|}{ SUVmax u trung bình } & \multicolumn{2}{|c|}{$14,7 \pm 6,1$} \\
\hline \multicolumn{2}{|c|}{ SUVpeak u trung bình } & \multicolumn{2}{|c|}{$11,5 \pm 5,2$} \\
\hline \multicolumn{2}{|c|}{ SUVmean u trung bình } & \multicolumn{2}{|c|}{$6,7 \pm 2,3$} \\
\hline
\end{tabular}

Các BN có tuổi phát hiện bệnh trung bình $57,9 \pm 6,9$; toàn bộ là nam giới. Điểm toàn trạng ECOG 0: $43,3 \%$ và ECOG 1-2: $56,7 \%$. Tỷ lệ $B N$ có độ mô học 1-2: $58,3 \%$ và độ $3: 38,3 \%$. Giai đoan bệnh II-IIIA chiếm 53,3\%, IIIB-IIIC chiếm $46,7 \%$. Phác đồ hóa chất được chỉ định chủ yếu là Paclitaxel/Carboplatin (80\%). Giá trị trung bình của SUVmax, SUVpeak và SUVmean của khối u tương ứng là $14,7 \pm 6,1,11,5 \pm 5,2$ và $6,7 \pm 2,3$.

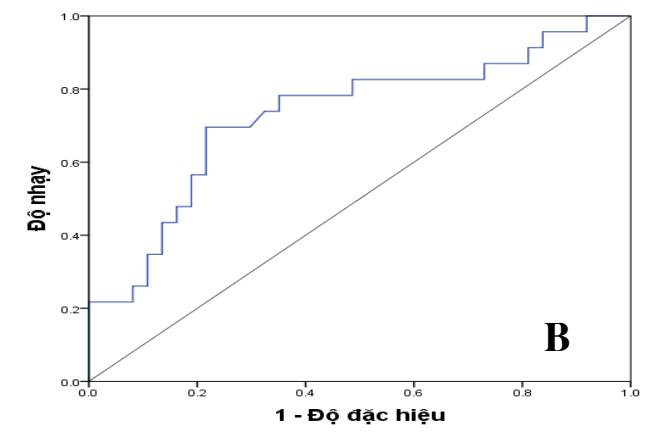

Biểu đồ 2: Đánh giá đáp ứng điều trị (hình A) và đường cong ROC của SUVmean trong dưr báo đáp ứng hoàn toàn (hinh $B$ )

Kết quả tỷ lệ đáp ứng hoàn toàn sau điêu trị là $38,3 \%$. Phân tích đường cong ROC cho thấy SUVmean u có ý nghĩa dự báo đáp ứng hoàn toàn với $A U C=0,73, p=0,00$. Tại ngưỡng 6,1 , SUVmean có độ nhạy, độ đặc hiệu, độ chính xác là $69,6 \%, 78,4 \%$ và $75 \%$.

Bảng 2: Phân tích hôi quy các thông số tiên lượng sống thêm Phân tích đơn biến

\begin{tabular}{|c|c|c|c|c|c|c|}
\hline \multirow{2}{*}{ Thông số } & \multicolumn{3}{|c|}{ OS } & \multicolumn{3}{c|}{ PFS } \\
\cline { 2 - 6 } & HR & $\mathbf{9 5 \% C I}$ & $\mathbf{P}$ & HR & $\mathbf{9 5 \%} \mathbf{C I}$ & $\mathbf{p}$ \\
\hline Giai đoạn bệnh (II, IIIA với IIIB, IIIC) & 1,28 & $0,53-3,05$ & 0,59 & 1,70 & $0,83-3,44$ & 0,15 \\
\hline Chiều dăi u $(<5 \mathrm{~cm}$ với $>5 \mathrm{~cm})$ & 1,70 & $0,69-4,2$ & 0,25 & 1,31 & $0,64-2,68$ & 0,46 \\
\hline
\end{tabular}




\begin{tabular}{|c|c|c|c|c|c|c|}
\hline $\begin{array}{c}\text { Phác đô hóa chất } \\
\text { (5FU/Cis với Pac/Car) }\end{array}$ & 1,03 & $0,63-1,67$ & 0,92 & 0,90 & $0,58-1,40$ & 0,64 \\
\hline SUVmax u & 1,06 & 13 & 0,08 & 1,04 & $0, \mathrm{C}$ & 0,11 \\
\hline SUVpeak u & 1,07 & & 0 & 1.06 & & 0,07 \\
\hline SUVmean u & 1,18 & 1,0 & 0,05 & 1,12 & 1,28 & 0,07 \\
\hline SUVmean u $(<6,1$ với $>6,1)$ & 4,50 & $1,51-13,44$ & 0,01 & 4,08 & $1,65-10,07$ & 0,00 \\
\hline \multicolumn{7}{|c|}{ Phân tích đa biến } \\
\hline SUVr & 6,74 & $1,40-32,39$ & 0,02 & 6,53 & $1,89-22,55$ & 0,00 \\
\hline
\end{tabular}

Phân tích hồi quy đa biến cho thấy SUVmean > 6,1 có ý nghĩa tiên lượng độc lập không thuận lợi cho sống thêm toàn bộ $(H R=6,74, p=0,02)$ và sống thêm bệnh không tiến triển $(H R=6,53, p=0,00)$.

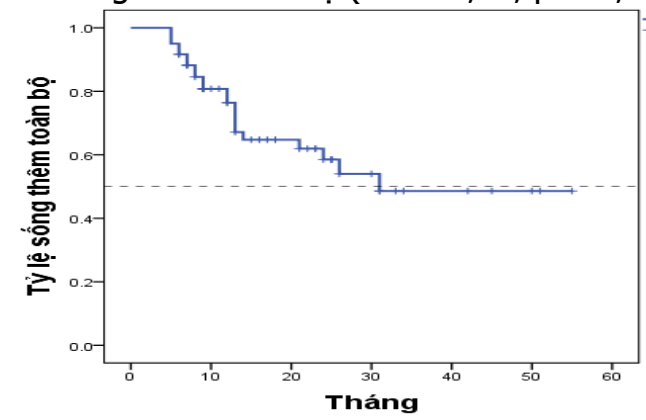

A

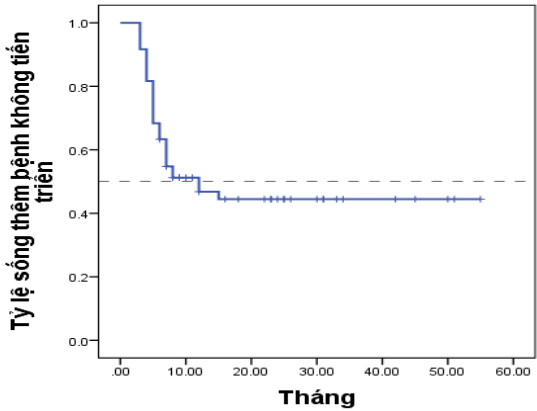

B

Biểu đồ 2. Đường cong Kaplan-Meier biểu diễn sống thêm toàn bộ (hình A) và sông thêm bệnh không tiến triển (hình B).

Trung vị thời gian theo dõi là 13 tháng. Trung vị thời gian sống thêm toàn bô là 31 tháng với tỷ lệ sông thêm toàn bộ sau 1,2 và 4 năm tương ứng là $76,4 \%, 58,5 \%$ và $48,6 \%$. Trung vị thời gian sống thêm bệnh không tiến triển là 12 tháng. Tỷ lệ sống thêm bệnh không tiến triển tại thời điểm 1,2 và 4 năm là $46,8 \%, 44,4 \%$ và $44,4 \%$.
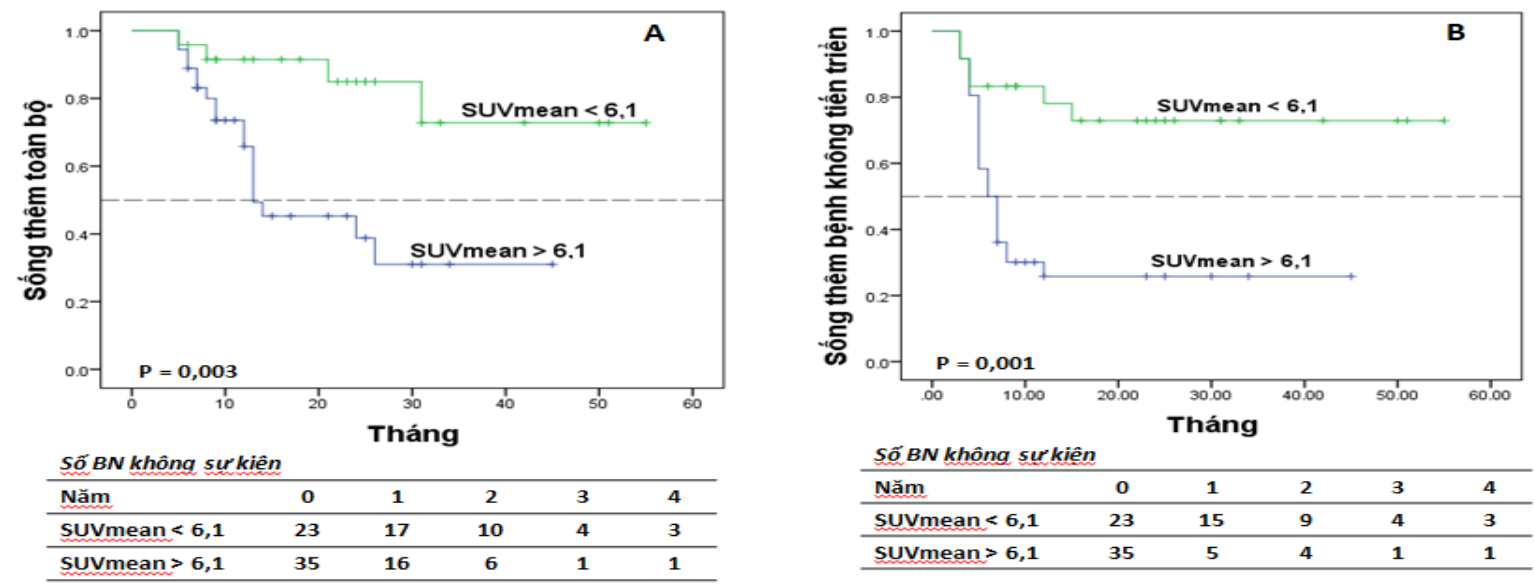

Biểu đồ 0. Đường cong Kaplan-Meier biểu diễn sống thêm toàn bộ (hình A) và sống thêm bệnh không tiên triển (hình B) theo ngưỡng SUVmean

Tỷ lệ sống thêm toàn bộ tại thời điểm 4 năm ở nhóm có chỉ số SUVmean u $<6,1$ cao hơn nhóm còn lại tương ứng là $72,8 \%$ và $31,0 \%(p<0,05)$. Tỷ lệ sống thêm bệnh không tiến triển tại thời điểm 4 năm ở nhóm SUVmean u < 6,1 cao hơn nhóm còn lại tương ứng là $72,9 \%$ và $25,8 \%(p<0,05)$.

Bảng 3. Giá trị dự báo sống thêm toàn bộ và sông thêm bệnh không tiến triển của các thông số SUV

\begin{tabular}{|c|c|c|c|c|c|c|}
\hline \multirow{2}{*}{ Thông số } & \multicolumn{3}{|c|}{ OS } & \multicolumn{3}{c|}{ PFS } \\
\cline { 2 - 7 } & AUC & $\mathbf{9 5 \%}$ CI & p & AUC & $\mathbf{9 5 \%}$ CI & p \\
\hline SUVmax & 0,64 & $0,50-0,78$ & 0,07 & 0,67 & $0,53-0,80$ & 0,03 \\
\hline SUVpeak & 0,64 & $0,50-0,78$ & 0,07 & 0,68 & $0,54-0,81$ & 0,02 \\
\hline SUVmean & 0,67 & $0,53-0,81$ & 0,03 & 0,69 & $0,55-0,84$ & 0,01 \\
\hline
\end{tabular}


SUVmean u có giá trị dự báo sống thêm toàn bộ với $A U C=0,67, p<0,05$. Tất cả các thông số SUV đều có khả năng dự báo sống thêm bệnh không tiến triển. Trong đó, SUVmean u có giá trị dự báo cao nhất với $A U C=0,69, p=0,01$.
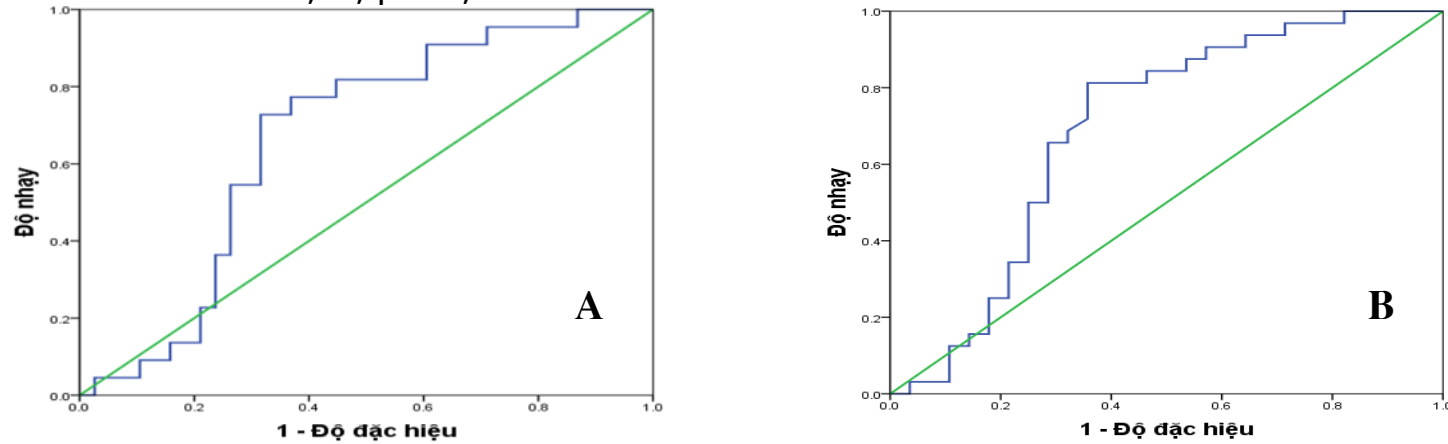

Biểu đồ 4. Đường cong ROC của SUVmean trong dự báo sông thêm toàn bộ (hình A) và và sống thêm bệnh không tiến triển (hình B)

Với ngưỡng 6,1, SUVmean u có độ nhạy, độ đặc hiệu, độ chính xác trong dự báo sống thêm toàn bộ và sống thêm bệnh không tiến triển tương ứng là $81,8 \%, 52,6 \%, 63,3 \%$ và $81,2 \%, 64,3 \%, 73,3 \%$.

\section{BÀN LUẬN}

Kết quả điều trị hoá xạ trị triệt căn cho thấy tỷ lệ sống thêm toàn bộ và sổng thêm bệnh không tiến triển 4 năm tương ứng là $48,6 \%$ và $44,4 \%$. Kết quả này tương đương hoặc thấp hơn một số nghiên cứu trên thế giới. Kết quả nghiên cứu của Takahashi cho thây tỷ lệ sống thêm toàn bộ và sống thêm bệnh không tiển triển 3 năm và 5 năm lần lượt là $54,1 \%, 36,5 \%$ và $49,7 \%$, 36,5\% [5]. Theo Lee, hóa - xạ triệt căn UTTQ có tỷ lệ sống thêm toàn bộ 3 năm là $54,5 \%$ [8]. Tỷ lệ sống thêm bệnh không tiến triển 3 năm trong nghiên cứu này thấp $(24,2 \%)$ có thể do liều xạ trị thấp hơn các nghiên cứu khác (trung vị tổng liều xạ 54Gy). Nghiên cứu của Han và cs trên 90 BN ung thư biểu mô vảy sau hóa - xạ triệt căn cho thấy tỷ lệ sống thêm toàn bộ 3 và 5 năm là $54,1 \%$ và $49,7 \%$; tỷ lệ sống thêm bệnh không tiến triển tương ứng là $36,5 \%$ và $36,5 \%$ [6].

Các thông số đánh giá giá trị hấp thu chuẩn định lượng trên ${ }^{18}$ F-FDG PET/CT gồm SUVmax, SUVmean và SUVpeak. SUVmax là giá trị SUV lớn nhất đo được tại một điểm ảnh (pixel) trong khối u. Thông số này được sử dụng rộng rãi vì nó không phụ thuộc vào người đo. Tuy nhiên, do tính không đồng nhất của khối u nên SUVmax không đại diện cho toàn bộ hoạt tính của cả khối u đó. SUVmean là giá trị trung bình hoạt tính chuyển hóa của khối u, nó phụ thuộc vào cách xác định thể tích u. Chỉ số SUVpeak là giá trị SUV trung bình cao nhất của một vùng quan tâm hình cầu có thể tích $1 \mathrm{ml}$ (đường kính $1,2 \mathrm{~cm}$ ) đặt trong khối u, thường dùng trong đánh giá đáp ứng điều trị. Một số nghiên cứu hiện nay đặt ra giả thuyết liệu các thông số đánh giá mức độ hấp thu ${ }^{18} \mathrm{~F}-\mathrm{FDG}$ trên hình ảnh PET/CT trước điều trị có ý nghĩa tiên lượng đáp ứng và sống thêm ở bệnh nhân UTTQ. Trong nghiên cứu của chúng tôi, các thông số như giai đoạn bệnh, kích thước u và phác đồ hóa trị đều không có ý nghĩa tiên lượng sống thêm. Thay vào đó, chính thông số chuyển hóa của ${ }^{18}$ F-FDG $P E T / C T$ mà cụ thể là SUVmean mới có vai trò trong tiên lượng kết quả điều trị.

Giá trị các thông số SUV của ${ }^{18}$ F-FDG PET/CT trước điều trị trong tiên lượng sống thêm toàn bộ: Trong nghiên cứu của chúng tôi, SUVmean $>6,1$ có ý nghĩa tiên lượng không thuận lợi cho sống thêm toàn bộ $(H R=6,74, p$ $=0,02$ ). SUVmean có giá trị dự báo sống thêm toàn bộ với độ nhạy, độ đặc hiệu, độ chính xác là $81,8 \%, 52,6 \%, 63,3 \%$. Một số nghiên cứu cho thây SUVmax u trước điều trị có giá trị tiên lượng sống thêm toàn bộ trong hóa - xạ trị triệt căn UTTQ. Theo Atsumi, SUVmax u có ý nghĩa tiên lượng kết quả sống thêm toàn bộ. Tỷ lệ sống thêm toàn bộ 2 năm của nhóm SUVmax < 10 là $100 \%$, cao hơn nhóm còn lại là $41 \%$ ( $p$ < $0,05)$ [2]. Bên cạnh đó, SUVmean và các thông số đại diện cho gánh nặng khối u như MTV (metabolic tumor volume) và TLG (total lesion glycolysis) cũng được nhắc tới trong các nghiên cứu gần đây. Theo Hong và $\mathrm{CS}$, các thông số có giá trị dự báo sống thêm toàn bộ gồm TLG, MTV và SUVmean của u. Trong đó TLG có giá trị nhất với $A U C=0,69, p=0,04$. Với ngưỡng 232,98, TLG có độ nhạy $71,4 \%$ và độ đặc hiệu $76,5 \%$ [4] Phân tích gộp của Han và cs chỉ ra MTV và TLG có vai trò tiên lượng sông thêm toàn bộ với HR tương ứng là 2,26 và 2,23 [6]. 
Giá trị của các thông số SUV ${ }^{18}$ F-FDG PET/CT trước điêuu trị trong tiên lượng sống thêm bệnh không tiến triển: Kết quả nghiên cứu của chúng tôi cho thấy SUVmean $>6,1$ có ý nghĩa tiên lượng không thuận lợi cho sống thêm bệnh không tiến triển $(H R=6,53, p=0,00)$. Các thông số SUVmax u, SUVpeak u và SUVmean u đều có khả năng dự báo sống thêm bệnh không tiến triển. Trong đó, thông số SUVmean u có giá trị dự báo cao nhất với $A U C=0,69, p=0,01$. Với ngưỡng 6,1, SUVmean u có độ nhạy $81,2 \%$, độ đặc hiệu $64,3 \%$, độ chính xác 73,3\%. Một số nghiền cứu đã chỉ ra vai trò hạn chế của thông số SUVmax u trước điều trị trong tiên lượng sống thêm bệnh không tiến triển. Nghiên cứu của Atsumi và cs cho thấy nhóm SUVmax < 10 có tỷ lệ sống thêm bệnh không tiến triển 2 năm cao hơn nhóm còn lại lần lượt là $73 \%$ và $19 \%(P<$ $0,05)$, tuy nhiên thông số này không có ý nghĩa tiên lượng trong phân tích đa biến [2]. Bên cạnh đó, vai trò các thông số MTV và TLG được nhắc tới nhiều hơn trong các nghiên cứu gần đây. Các thông số này có thể bao gồm cả u và hạch nên có tính đại diện cao hơn SUV. Theo Takahashi, MTV và TLG tổng của u và hạch trước điều trị là những yếu tố tiên lượng độc lập cho sống thêm bệnh không tiến triển; SUVmax u không có ý nghĩa tiên lượng [5]. Theo Lemarignier, MTV trước điều trị có ý nghĩa tiên lượng độc lập cho bệnh không tiến triển [3]

Nhìn chung, các nghiên cứu cho thây các thông số hấp thu chuẩn ${ }^{18} \mathrm{~F}-\mathrm{FDG}$ PET/CT trước điêu trị có khả năng tiên lượng đáp ứng điều trị và sống thêm. Các thông số được khai thác nhiều hơn cả là SUVmax, SUVmean và gân đây là MTV và TLG. SUVmax chỉ đơn thuần phản ánh mức độ chuyển hóa của một đơn vị điểm ảnh trong khối u. Trong khi đó, khối u là tập hợp nhiều tế bào ác tính có mức độ chuyển hóa không đồng nhất, đáp ứng với điều trị của mỗi tế bào lại khác nhau. Do vậy, SUVmax không có tính đại diện cho chuyển hóa khối u. Thông số SUVmean có thể đại diện cho phần lớn khối u do là trung bình các giá trị SUV của tất cả các điểm ảnh trong khối u. Có thể do vậy mà chúng tôi chỉ ghi nhận vai trò tiên lượng của SUVmean. Kết quả nghiên cứu của chúng tôi có thể gợi ý trong thực hành điêu trị UTTQ tế bào vảy, cần có thái độ xử trí, điều trị và theo dõi chặt chẽ hơn trên nhóm BN có SUVmean u > 6,1 do khả năng đáp ứng điều trị kém và tiên lượng xấu.

Điểm hạn chế trong nghiên cứu của chúng tôi là chưa khai thác được ý nghĩa tiên lượng của các thông số về tải lượng khối u (tumor burden) như MTV (metabolic tumor volume), TLG (total lesion glycolysis) trong đánh giá kết quả điều trị. Đây cũng là những gợi ý cho hướng nghiên cứu tiếp theo của chúng tôi sử dụng các thông số này trong đánh giá đáp ứng điều trị và tiên lượng bệnh nhân UTTQ.

\section{KẾT LUẬN}

Các giá trị hấp thu chuẩn, đặc biệt là SUVmean trên ${ }^{18} \mathrm{~F}$-FDG PET/CT toàn thân trước điều trị có thể sử dụng để tiên lượng đáp ứng và sống thêm ở bệnh nhân ung thư thực quản biểu mô vảy điều trị hoá xạ trị triệt cắn. Cần tiến hành thêm các nghiên cứu về vai trò của các thông số đại diện cho gánh nặng khối u như MTV, TLG trong đánh giá và tiên lượng hiệu quả điều trị.

\section{TÀl LIỆU THAM KHẢO}

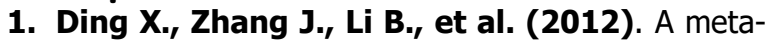
analysis of lymph node metastasis rate for patients with thoracic oesophageal cancer and its implication in delineation of clinical target volume for radiation therapy. Br J Radiol, 85(1019), 1110-1119.

2. Atsumi K., Nakamura $K_{\text {., }}$ Abe $K_{\text {, }}$ et al. (2013). Prediction of outcome with FDG-PET in definitive chemoradiotherapy for esophageal cancer. J Radiat Res (Tokyo), 54(5), 890-898.

3. Lemarignier C., Di Fiore F., Marre $C_{.}$, et al. (2014). Pretreatment metabolic tumour volume is predictive of disease-free survival and overall survival in patients with oesophageal squamous cell carcinoma. Eur J Nucl Med Mol Imaging, 41(11), 2008-2016.

4. Hong J.H., Kim H.H., Han E.J., et al. (2016). Total Lesion Glycolysis Using 18F-FDG PET/CT as a Prognostic Factor for Locally Advanced Esophageal Cancer. J Korean Med Sci, 31(1), 39.

5. Takahashi N., Umezawa R., Takanami K., et al. (2018). Whole-body total lesion glycolysis is an independent predictor in patients with esophageal cancer treated with definitive chemoradiotherapy. Radiother Oncol, 129(1), 161-165.

6. Han S., Kim Y.J., Woo S., et al. (2018). Prognostic Value of Volumetric Parameters of Pretreatment 18F-FDG PET/CT in Esophageal Cancer: A Systematic Review and Meta-analysis. Clin Nucl Med, 43(12), 887-894.

7. Mantziari S., Pomoni A., Prior J.O., et al. (2020). 18F- FDG PET/CT-derived parameters predict clinical stage and prognosis of esophageal cancer. BMC Med Imaging, 20(1), 7.

8. Lee S., Choi Y., Park G., et al.'(2021). 18F-FDG PET/CT Parameters for Predicting Prognosis in Esophageal Cancer Patients Treated With Concurrent Chemoradiotherapy. Technol Cancer Res Treat, 20, 153303382110246.

9. Watanabe N., Jeremić B., and International Atomic Energy Agency (2008), The role of PET/CT in radiation treatment planning for cancer patient treatment., International Atomic Energy Agency, Vienna. 